Kristin Næss-Andresen, jordmor med mastergrad i reproduktiv helse, føde og barselavdelingen ved OUS, Ullevål.
Ann Kristin Bjørnnes, jordmor med mastergrad i helse og sosialfag, høyskolelektor ved Høgskolen i Oslo og Akershus.

\title{
Norsk lov stigmatiserer mødre med hiv
}

\author{
I Norge er det straffbart for mødre med hiv å amme. Dette rammer oftest kvinner med \\ minoritetsbakgrunn og kan gjøre disse mødrene ytterligere isolerte og stigmatiserte.
}

denne artikkelen vil vi belyse om det er hensiktsmessig at hiv-positive kvinner som ammer sine barn kan bli straffet med fengsel. Artikkelen er basert på våre egne erfaringer med å følge opp hiv-positive kvinner ved Oslo universitetssykehus og på nyere forskning innen området.

\section{Bakgrunn}

I Norge er cirka 1500 kvinner diagnostisert med hiv (1). Dette er et relativt lavt antall sett i et globalt perspektiv. De fleste av kvinnene har minoritetsbakgrunn og kommer fra land hvor helsemyndigheter anbefaler hiv-positive å amme sine barn. Denne gruppen hiv-positive har fătt lite oppmerksomhet i Norge, til tross for de store utfordringene de møter med stigmatisering og diskriminering. Smittevernloven er en av fak-

\section{Hovedbudskap}

Med denne artikkelen ønsker vi å løfte fram om det er hensiktsmessig å ha en smittevernlov som truer hivpositive kvinner med fengsel dersom de velger å amme barnet sitt. I Norge har oppmerksomheten rundt hivdebatten ofte dreiet seg om seksualitet, og i hovedsak om menn som har sex med menn. Reproduktiv helse har fătt en relativt liten plass i den norske hiv-debatten. Vår erfaring tilsier at hiv-positive kvinner lever under ekstreme belastninger og at både kvinnene, barnet og helsepersonell er mer tjent med andre virkemidler for å forebygge spredning enn dagens smittevernlov.

\section{Søkeord}

Les mer og finn litteraturhenvisninger på våre nettsider. > Amming | Fødsel / Kronisk / Sykdom ) Smitte, Jus torene som kan bidra til å gjøre livssituasjonen ytterligere besværlig for disse hiv-positive kvinnene.

Straffelovens paragraf 155 handler om overføring av allmennfarlig smitte, altså straff for å smitte et annet menneske med en sykdom staten anser som ekstremt farlig. Loven er ment å beskytte befolkningen i landet mot enten ekstremt smittsomme sykdommer, sykdommer som har ekstra alvorlige konsekvenser eller begge deler (2). Hvis en hiv-positiv kvinne velger å amme sitt barn i Norge, vil hun bli berørt av denne paragrafen ettersom hun i henhold til loven utsetter sitt barn for smitte. Man kan straffes med fengsel i inntil seks år ved forsettlig overtredelse og med fengsel $\mathrm{i}$ inntil tre år ved uaktsom overtredelse (2). Med bakgrunn i straffelovens paragraf 155 kan en hiv-positiv kvinne som ammer sitt barn risikere å bli dømt til fengsel i inntil seks år.

Over 33 millioner mennesker lever med hiv/ aids, hittil er 25 millioner døde som følge av sykdommen (3). I et globalt perspektiv er spørsmål knyttet til reproduktiv helse særlig aktuelt fordi hiv-overføringen fra mor til barn og generasjonsoverskridende smittespredning fra menn til yngre kvinner gjør det vanskelig å stoppe pandemien (4).

\section{Hiv-positive kvinner}

Flertallet av gruppen nysmittede i Norge finnes blant flyktninger og asylsøkere, og mange av dem er kvinner (5). Ved ankomst til Norge tilbys denne gruppen hiv-testing. De fleste som blir diagnostisert som hiv-positive gjennom denne screeningen var selv ukjente med sin hiv-status før de kom til Norge. Gruppen representerer kvinner og menn i fertil alder, som allerede er i en vanskelig livssituasjon før de får diagnosen.
Mange av dem bor trangt på asylmottak, og de fleste har ikke avklart oppholdstillatelse i Norge. Når de blir diagnostisert med hiv, trenger de mye hjelp og støtte, samtidig som oppfølgingen er begrenset (5).

Det er et dilemma at hiv-debatten i Norge ofte har dreiet seg om seksualitet, og i hovedsak knyttet til gruppen menn som har sex med menn. Reproduktiv helse har fått en relativt liten plass i den norske hiv-debatten. Dette er betenkelig da de fleste nysmittede, som nevnt ovenfor, er asylsøkere og flyktninger.

Hiv-positive kvinner er en utsatt gruppe, svært få eller ingen av dem vil være åpne om sin hivstatus, og muligheten for sosial støtte og rådgivning er derfor begrenset (6). Kvinnene opplever et dilemma når de føder barn dersom de ikke våger å være åpne om at de lever med hiv. I Norge eksisterer en sterk ammekultur, men hiv-positive kvinner kan ikke amme sine barn på grunn av muligheten for å smitte dem. Dette er vanskelig for mange av kvinnene, særlig de som kommer fra en kultur hvor man anbefales å amme sine barn, uavhengig av deres hiv-status.

I Norge får hiv-positive gravide tilbud om ekstra oppfølging i svangerskap, fødsel og barseltid. Denne oppfølgingen er iverksatt for å forebygge hiv-smitte fra mor til barn. De fleste hiv-positive kvinner har de samme ønsker om barn som befolkningen for øvrig, men barneønsket hos hivpositive avhenger av flere faktorer som fysiske helse, respons på behandling, kultur, tradisjon, og antall barn de har før de ble kjent med sin diagnose som hiv-positive (7)

\section{Morsrollen}

Å være hiv-positiv og vente barn, kanskje for første gang, er en svært vanskelig livssituasjon 
for mange av familiene det angår. Forskning anerkjenner overgangen til foreldrerollen som en av de store hendelsene i livet (8). Utviklingskrise er ofte brukt som en beskrivelse på nybakte foreldres erfaringer (9). Overgangen til morsrollen er en viktig og progressiv læreprosess for kvinner som venter barn. Prosessen starter allerede i svangerskapet og fortsetter etter fødselen, hvor samspillet med det nyfødte barnet spiller en stor rolle (10).

Fødselen er det første møtet mellom det nye barnet og foreldrene, og en avgjørende hendelse i både kvinnens og mannens liv. Fødselen kan ha stor betydning, fordi den markerer innledningen til nye roller, men også til nye relasjoner som skal etableres (11). Barn fødes inn i en sammenheng hvor kvaliteten på relasjonen mellom foreldrene og deres forutsetninger for omsorg for barnet vil påvirke det nyfødte barnets livskvalitet og helse (12). Hivpositive mødre lever i en stressituasjon som kan påvirke barnets oppvekstvilkår negativt. Tilknytningsteori tillegger barnets omgivelser avgjørende betydning for dets utvikling. Omsorgspersonenes samspill med barnet kan støtte eller hemme den psykiske modningen $(8,13)$.

Kvinnens alder, egen historie og forhold til egne foreldre, sivilstatus og grad av sosial støtte både fra partner og andre, påvirker overgangen til morsrollen. Grad av sosial støtte har vist seg å være den mest betydningsfulle påvirkningsfaktoren for den gravide kvinnen (10). I mange kulturer finnes det et unikt kvinnefellesskap som blir særlig betydningsfullt når man befinner seg i et fremmed land.

Redselen for at hiv-statusen skal bli kjent kan føre til at mange kvinner mister dette

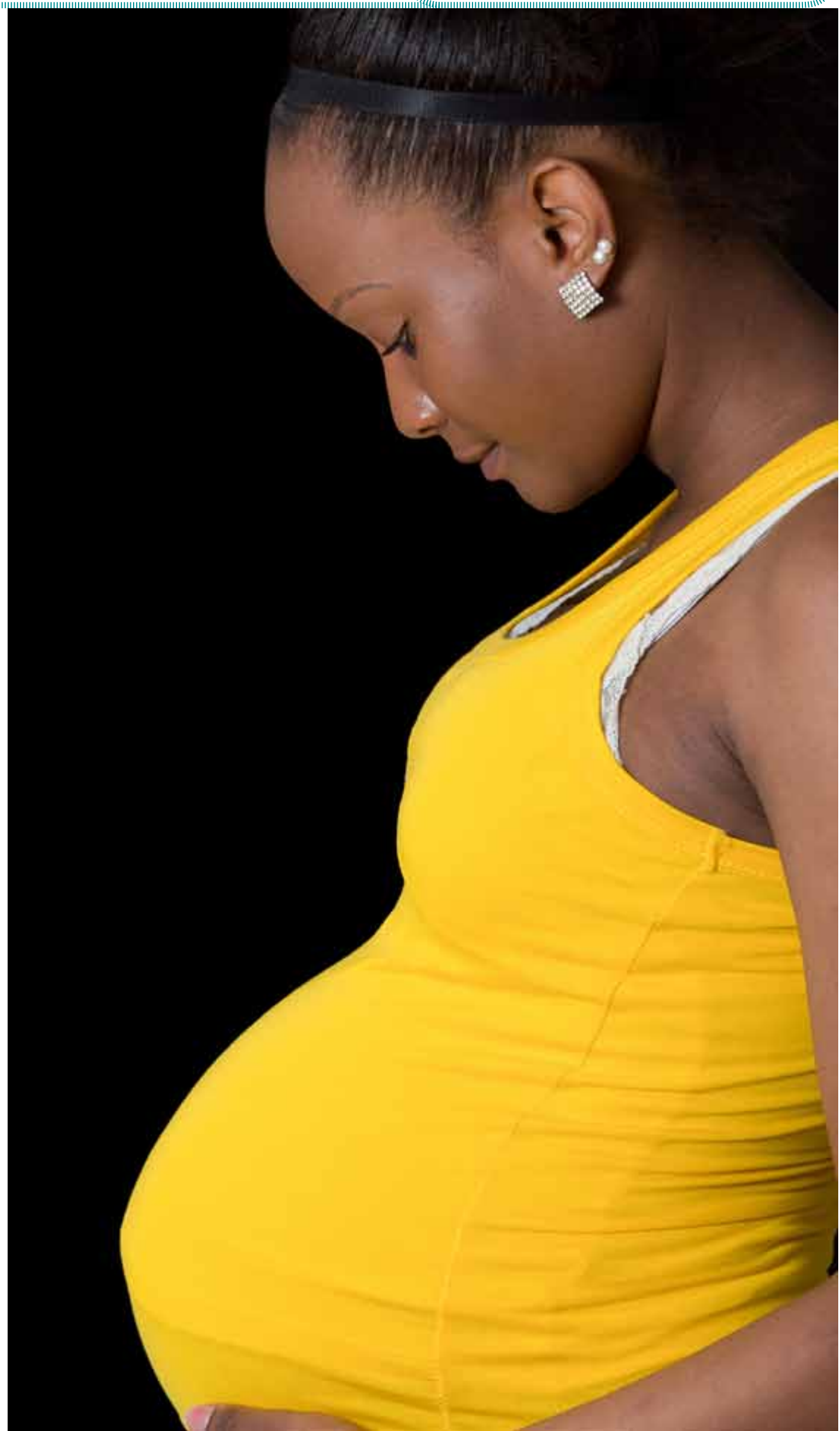

GRAVIDITET OG HIV: De fleste kvinner med hiv-diagnose i Norge har minoritesbakgrunn. For disse representerer svangerskap, fødsel og livet med et nyfødt barn ekstra utfordinger. Kvinnen på bildet har ingen tilknytning til artikkelen. Illustrasjonsfoto: Michel Borges/NTBscanpix. 
viktige kvinnefellesskapet. I en levekårsundersøkelse utført av FAFO ble det framhevet at manglende åpenhet om hiv-diagnosen er en stor utfordring for hiv-positive (6). Nærmeste familie og nettverk er ofte ikke informert om diagnosen. De fleste hiv-positive ønsker at det skal forbli slik på grunn av smittefrykt, risikoen for stigmatisering og fordommer (5).

\section{Erfaringer fra OUS}

Ved Oslo universitetssykehus, avdeling Ullevål jobber en gruppe jordmødre og gynekologer med oppfølging av hiv-positive gravide. Kvinneklinikken har den største konsentrasjonen av hiv-positive gravide i Norge, og det forløses ner kan føle seg annerledes og føre til isolasjon og ensomhetsfølelse. Amming er forbundet med sterke normative føringer. En kvinne som ikke ammer barnet sitt kan føle at hun ikke tilfredsstiller kravet om å være en "god mor». Man gir sjelden morsmelkerstatning til friske nyfødte i Norge, og helsegevinsten ved amming er allment kjent. Hiv-positive kvinner pålegges imidlertid å flaskeernære sine nyfødte. Familien vil få opplæring i å flaskeernære barnet med hensyn til blandingsforhold og hygieniske aspekter. Fordi familien er engstelig for å overføre hiv-smitte til barnet, opprettholdes dette alternativet, men det innebærer store utfordringer. Noen hiv-smittete kvinner vi har

\section{«Hiv-positive mødre lever i en stressituasjon som kan påvirke barnets oppvekstvilkår negativt.»}

cirka 20 hiv-positive kvinner hvert år, enten ved keisersnitt eller vaginal forløsning.

Våre erfaringer viser at det er en glede for de fleste hiv-positive å bli gravide, men mange er redde for å smitte fosteret, til tross for at smitterisikoen er relativ lav fordi de fleste hivpositive gravide har god respons på antiviral behandling. Nærmest alle gir uttrykk for at de er engstelig for at personalet ved sykehuset ikke skal overholde taushetsplikten, og de er redde for at familie eller venner skal få kjennskap til hiv-statusen deres. Flere har gitt uttrykk for at de føler seg stigmatiserte av personalet og rutinene på avdelingene. Ved Oslo universitetssykehus, så vel som ved andre norske sykehus, vil pasienter som lever med hiv bli behandlet i tråd med et blodsmitteregime. Dette regimet innebærer skilting av dører, og ekstrautstyr vil være tilgjengelig på pasientrommet for å forebygge smitte.

Mange av de hiv-positive kvinnene uttrykker redsel for at familie og venner skal forstå at de er hiv-smittet som følge av disse tiltakene. Mange hiv-positive gravide blir forløst med keisersnitt for å forebygge smitte fra mor til barn gjennom fødselskanalen. Dette tilsier et lengre sykehusopphold. Pårørende ønsker å besøke mor og barn under sykehusinnleggelsen. Dette kan øke sjansen for at kvinnens hiv-status blir kjent.

\section{Føler seg annerledes}

Ved norske barselavdelinger er det mye fokus på amming og utfordringer knyttet til dette, noe som igjen kan bidra til at hiv-positive kvin- møtt har opplevd det som så vanskelig ikke å amme at de har diskutert muligheten for likevel å amme sine barn på tross av smittefaren. Hvis de hadde vært i sitt hjemland, ville de antakeligvis blitt anbefalt å amme, til tross for at smitterisikoen er mye høyere i disse landene fordi man ikke har tilgang til optimal behandling; Highly Active Anti Retroviral Treatment (HAART) (14). Noen av kvinnene har uttrykt at flaskeernæring av barnet kan gjøre at andre forstår at de er smittet med viruset fordi de kommer fra høyendemiske land. Denne redselen for at deres hiv-status skal bli kjent gjennom at de ikke ammer, er svært problematisk og vitner om den generelle stigmatiseringen hiv-positive utsettes for.

\section{Lav risiko}

Er det riktig, på bakgrunn av de momentene vi her har trukket fram, at hiv-positive kvinner som ønsker å amme skal straffes med fengsel i inntil seks år, slik den nåværende smittevernloven tilsier? Forskning, blant annet publisert i Lancet Infectious Diseases, The Kesho Bora Study (14), viser at det er tryggere for hiv-positive å amme nå enn før hvis hun bruker en kombinasjonsbehandling med tre antiretrovirale medikamenter gjennom svangerskap, fødsel og ammeperiode. Dette behandlingsregimet kan redusere overføringen av hiv til barnet med opp til 54 prosent $\mathrm{i}$ ammeperioden. Mødre som er fullt virussupprimert ved fødsel har lav risiko for å smitte de får trippelbehandling med antiretrovirale barna sine (2,7 prosent etter 12 måneder) når midler (14). Dette nye behandlingsregimet er svært gunstig for kvinner som lever med hiv, og som ikke trygt kan gi sine barn morsmelkerstatning. Behandlingsmetoden vil øke sjansene for at barnet holder seg friskt og ikke smittes av hiv-infeksjon. Av den grunn anbefales hiv-positive kvinner i Afrika å amme ettersom morsmelk er den beste ernæring for barnet (15) samt at amming vil beskytte mot dødelige barnesykdommer som lungebetennelse og diaré. Smitterisikoen ved amming vurderes til å være relativt begrenset (14).

\section{Global innsats}

UNAIDS (Joint United Nations Programme on HIV and AIDS) er FNs viktigste organ for en forsterket, helhetlig og global innsats mot hiv-epidemien. UNAIDS mener den norske lovgivningen kriminaliserer hiv-positive og bidrar til å redusere mulighetene for å begrense hiv-epidemien. De hevder at lovgivningen medfører mindre åpenhet omkring hiv, noe som igjen kan bidra til økt smittespredning (3). Loven kan bidra til å opprettholde stigmatiseringen av hiv-positive og medføre at de fortsetter å leve i taushet om sin hiv-status. Det hiv-positive kvinner trenger er mer oppmerksomhet og oppfølging slik at disse i større grad kan ta valg om svangerskap, fødsel og ernæring av barnet på et realistisk grunnlag og ikke ut fra frykt om straff.

\section{Behov for kunnskap}

To FAFO-rapporter framhever at det er behov for økt kunnskap om hiv blant helsepersonell og i befolkningen generelt. I tillegg etterlyses en mer helhetlig tilnærming til hiv-positive med særlig oppmerksomhet på informasjon om seksualitet, samliv og reproduktiv helse $(5,6)$. Myndighetene bør vie disse områdene større oppmerksomhet gjennom forskning og utvikling av ny kunnskap om denne gruppens behov. For framtiden ønsker man at hiv-behandlingen skal bli så effektiv at hiv-positive kvinner kan amme sine barn uten fare for smitteoverføring, og at deres barn kan nyte fordelene ved å bli ammet. Det er positivt at regjeringen nylig har satt ned et utvalg som skal vurdere hvor hensiktsmessig straffelovens paragraf 155 er. Ulike aspekter ved loven skal vurderes i lys av ny kunnskap og internasjonale anbefalinger. Utvalget, også kalt Syseutvalget, ledes av professor Aslak Syse og skal levere sin innstilling oktober 2012. Anbefalingene som Syseutvalget kommer til å legge fram høsten 
FAG

Smånytt

2012 blir betydningsfulle, og vi håper at lovverket kan utformes til det beste både for hivpositive kvinners reproduktive helse. Loven bør endres slik at Norges lovgivning er i tråd med FNs anbefalinger om å ikke kriminalisere hiv-positive.

\section{Avslutning}

Vi vil avslutte denne artikkelen med å understreke betydningen av økt oppmerksomhet på kunnskap og informasjon om hiv i samfunnet, slik at det blir lettere for hiv-positive å være åpne om sin hiv-status. Kvinnene vi har omtalt her lever under ekstreme belastninger. Vi mener at disse kvinnene, barna deres og helsepersonell er mer tjent med andre virkemidler enn smittevernloven for å forebygge spredning av hiv-epidemien i Norge. NOU Kvinners helse i Norge (1999:13) pekte på nødvendigheten av at kvinnene selv tar aktivt del i utformingen av helseomsorgen. Det betyr at for å fremme kvinners helse generelt og kvinners reproduktive helse spesielt, må deres egen innsikt og erfaringer anerkjennes som en viktig kunnskapskilde, også i utformingen av den nye smittevernloven. Vi venter spent på anbefalingene fra Syseutvalget! IIII

\section{LITTERATUR}

s.p.

Norge. Smittevernloven Oslo: lovdata.no; 2012

AIDS epidemic update: December 2009. Geneva, Switzerland: UNAIDS: 2009. 99 s.p.

4. Kallings LO. Intergenerational transmission gives HIV eternal life. LäkartidningenJF - Läkartidningen. 2011;108 (12): 661-3.

5. Fangen K. Levekår og livskvalitet blant hiv-positive. Oslo: Fafo; 2002.254 s.p.

Grønningsæter AB, Haug H, Mandal R, Nuland BR. Fra holdninger til levekår: liv med hiv i Norge i 2009 . Oslo: Forskningsstiftelsen FAFO; 2009. 166 s. p.

Andresen KN-. Family planning for women infected with HIV in sub - Saharan Africa: A review of the evidence [Masterdegree]: London 2008.

8. Hart S, Schwartz R. Fra interaksjon til relasjon: tilknytning hos Winnicott, Bowlby, Stern, Schore og Fonagy. Oslo: Gyldendal akademisk; 2009 . 278 s. p.

9. Brudal LF. Psykiske reaksjoner ved svangerskap, fødsel og barseltid. Bergen: Fagbokforl.; 2000. 195 s. p.

10. Emmanuel E, Creedy DK, St John W, Gamble J, Brown C. Maternal role development following childbirth among Australian women. Journal of Advanced Nursing. 2008;64(1): 18-26.

11. Fägerskiöld A. A change in life as experienced by first-time fathers. Scandinavian Journal of Caring Sciences. 2008;22(1): 64-71.

2. Nystrom K, Ohrling K. Parenthood experiences during the childss first year: literature review. Journal of Advanced Nursing. 2004;46(3): 319-30.

13. Söderström K. «Ensomt spedbarn søker kompetent omsorgsperson». Barn Soderstom K. Ensomt spedbarn soker kompetent on . Thes ke

The Kesho Bora Study $G$. Safety and effectiveness of antiretroviral drugs during pregnancy, delivery and breastfeeding for prevention of mother-tochild transmission of HIV-. The Kesho Bora Multicentre Collaborative Study rationale, design, and implementation challenges. Contemporary Clinical Trials. 2011;32(1): 12p.

15. Baerug A, Holmsen ST, Löland BF, Nylander G. Health effects of breas feeding - a myth? UtpostenJF - Utposten. 2011;40(5): 10-3.

16. Cullberg J. Krise og utvikling. København: Hans Reitzel; 2007. 227 s. p. 